\title{
Application of different feeding strategies in fed batch culture for pullulanase production using sago starch
}

\begin{abstract}
The production of pullulanase by Bacillus flavothermus KWF-1 in batch and fed batch culture were compared using $2 \mathrm{~L}$ bioreactor. In batch culture, $0.0803 \mathrm{U} / \mathrm{mL}$ of pullulanase activity with specific activity of $0.0213 \mathrm{U} / \mathrm{mg}$ was produced by controlling the agitation speed and temperature at $200 \mathrm{rpm}$ and $50{ }^{\circ} \mathrm{C}$, respectively. Fed batch production was studied by feeding the culture with different sago starch concentrations in various feeding modes for enhanced pullulanase production. Exponential feeding mode at dilution rate of $0.01 / \mathrm{h}$ was the preeminent strategy for enhanced pullulanase production of $0.1710 \mathrm{U} / \mathrm{mL}$ with specific activity of $0.066 \mathrm{U} / \mathrm{mg}$. It had shown an increment of pullulanase production and specific activity by 2.1 and 3.1-fold, respectively when compared to batch culture. Increment of pullulanase activity in exponential feeding mode improved hydrolyzation of sago starch into maltotriose and panose by 4.5 and 2.5 -fold respectively compared to batch system.
\end{abstract}

Keyword: Pullulanase; Sago; Fed batch; Maltose; Maltotriose; Panose 